\title{
Uma dramaturgia tchekoviana
}

\section{Mickael de Oliveira}

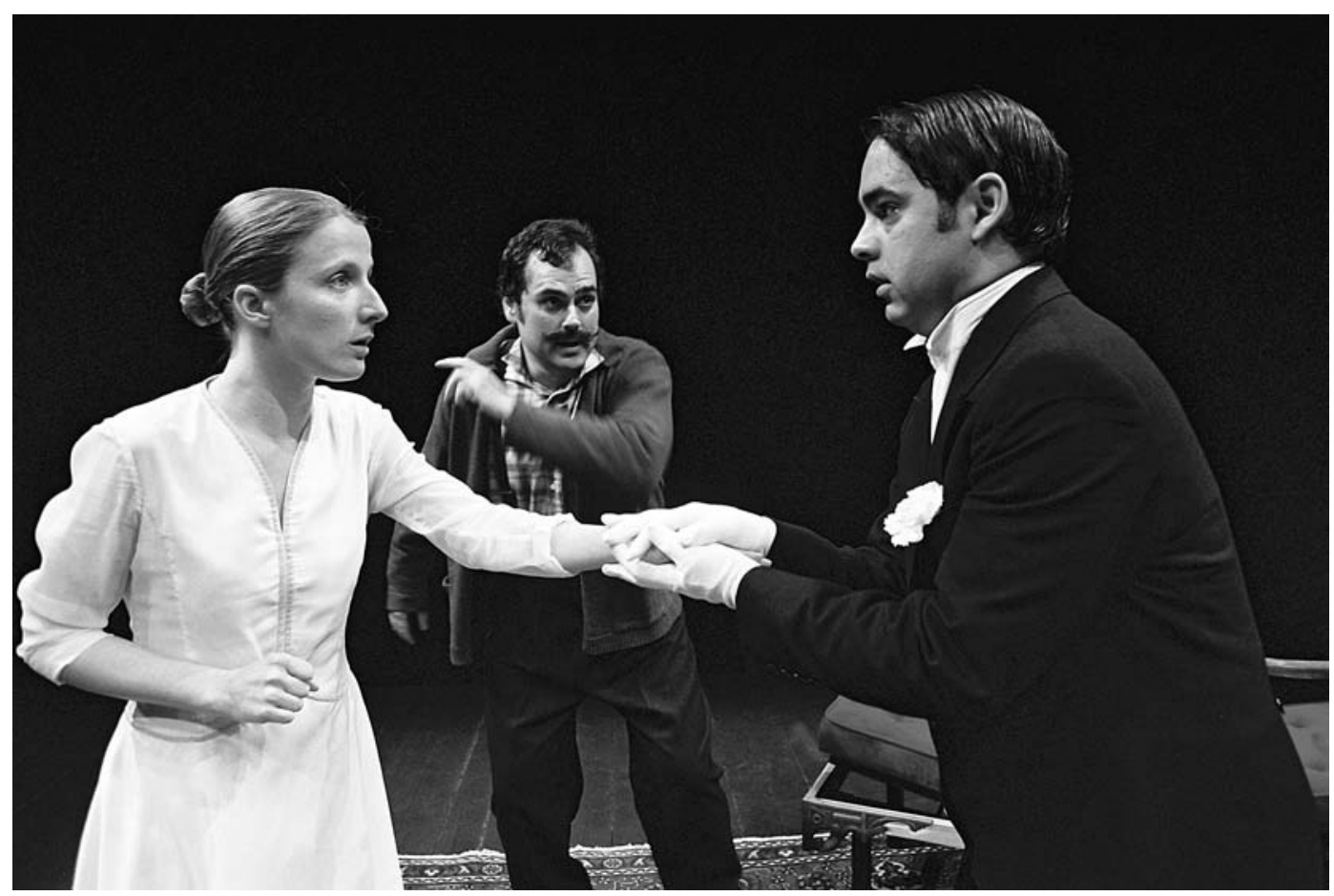
Assunção. Fotografia: Augusto Baptista. Operação de luz e som: Danilo Pinto. Produção: A Escola da Noite. Local e data de estreia: Coimbra, Oficina Municipal do Teatro, 15 de Março de 2007.

0 exercício da crítica teatral é uma actividade de risco, como aliás nos lembra o dossiê temático do anterior número da Sinais de cena. A crítica torna-se contudo uma actividade ainda um pouco mais complexa numa cidade como Coimbra. De facto, a tarefa de avaliar um espectáculo como Tchekov e a arte menor, independentemente das suas opções estéticas e referências teatrais, contrasta desde logo com o panorama cultural conimbricense, 0 qual tem levado uma existência teatral demasiado subnutrida, com efeitos tanto nos produtores como nos receptores (espectadores). Neste sentido, a companhia profissional A Escola da Noite, sob a direcção de António Augusto Barros, tem vindo a desempenhar também o trabalho de uma verdadeira instituição pública, resgatando o espaço teatral da cidade que a acolhe. Trata-se pois de uma tarefa de grande responsabilidade, em certa medida, partilhada com o que o Teatro Académido Gil Vicente vem oferecendo à vida artística da cidade, sobretudo nos últimos anos.
Esta última produção da Escola permitiu-nos rever em palco as peças curtas de Tchekov, nalguns dos seus mais célebres dramatículos: 0 trágico à força, 0 urso e 0 pedido de casamento constituem a primeira parte do espectáculo; O canto do cisne, Os malefícios do tabaco e O jubileu, a segunda parte. Esta é a ordem da apresentação, mas devemos desde já acrescentar que 0 canto do cisne é ele próprio dividido em fragmentos menores, ao longo da segunda parte, reforçando a lógica compositiva que domina a encenação. Como os títulos e a densidade textual sugerem, A Escola da Noite desenvolveu um trabalho que em termos puramente teatrais apresentava exigências tremendas. A interpretação dos actores assumiu um enorme esforço físico, além de um trabalho corporal deliberadamente estilizado, mais do que a construção complexa das personagens, geralmente estanques nas comédias de repertório. Esse esforço titânico envolveu um estudo de dramaturgia aprofundado, incluindo uma nova tradução, na qual devemos assinalar a qualidade 
Fotomontagem do grupo de actores: Silvia Brito Pessoa Júnior, Sofia Lobo, (Tchekov), Miguel Magalhães, Maria João Robalo e, em baixo, António Jorge.

Tchekove a arte menor (O urso), de Tchekov, enc. António Augusto Barros, A Escola da Noite, 2007 (António Jorge e Silvia Brito), fot. A Escola da Noite.
1 Encenação de Rogério de Carvalho, Junho de 2004 (ver Rui Pina Coelho, "Como se fosse a primeira vez: 0 cerejal", in Sinais de cena, n. 2 , Dezembro

de 2004, pp .87-89).

${ }^{2}$ Titulo que tem como

subtitulo Estudo dramático em um acto. A palavra "drama" encarna,

neste caso, o registo "sério" da peça. 0 canto do cisne aborda, através

de duas personagens, Svetlovídov, um velho actor (só, decadente) e o ponto, Nikita Ivánitch,

(igualmente só e decadente), que vão falando sobre o que é o abandono, não só numa despedida à vida, como também numa despedida ao teatro. impar no que diz respeito à sua transposição para o verbo cómico português. Este investimento teatral e verbal traduziu-se assim em três horas de espectáculo, em ritmo vivo na primeira parte e de tonalidade mais trágico-cómica na segunda parte. 0 riso e o sorriso tornam-se aliados do público durante quase todo o espectáculo, não só pela performance dos actores, mas também pela inteligência do humor e a cadência das palavras do autor russo. 0 espectador que esperasse um mero somatório de pequenas fábulas divertidas, em crescendo, sairia algo surpreendido pelo tom mais sóbrio da segunda parte, graças ao dramatículo 0 canto do cisne, embora este constitua justamente o motivo agregador da dramaturgia do encenador, tornando-se assim a parte fundamental para a compreensão da própria encenação.

Centremo-nos então em Tchekov e a arte menor. Não é a primeira vez que a Escola da Noite produz um espectáculo com a autoria do escritor russo. Depois d' 0 cerejal $^{1}$, a companhia envereda agora pelos caminhos tchekovianos com o encenador António Augusto Barros, que optou por abordar a dimensão "menor" do dramaturgo russo. 0 termo "menor" que aparece no título do espectáculo escreve-se em tom de provocação, já que a companhia acaba justamente por mostrar a importância destes textos. Seriam "menores" se os comparássemos às obras-primas do autor, como Tio Vânia, A gaivota ou 0 cerejal. Os dramatículos terão sido afinal vítimas "menores" porque contraíram in utero duas doenças: a pequenez textual e o género cómico com contornos vaudevilescos. 0 próprio Tchekov encarava estes textos como pequenos divertimentos sem grande importância, sendo portanto o primeiro a não Ihes dar muita relevância. Contudo, se estes dramas curtos assumem certa frivolidade, trivialidade, comicidade e ligeireza, não deixam de manifestar algum do desalento que caracteriza grande parte da obra "maior" tchekoviana.
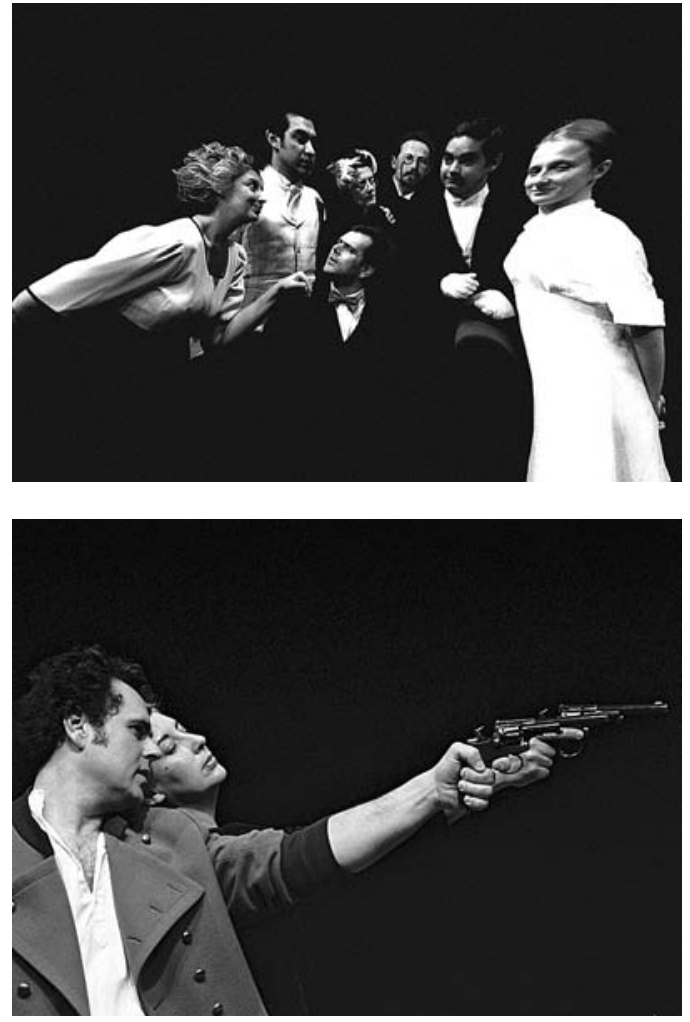

A dramaturgia trabalhada pelo encenador d'A Escola da Noite à volta dos textos concentrou-se na exploração cómica e ancestral dos conflitos conjugais, que remonta aos tempos mais antigos da comédia, em autores como Aristófanes, por exemplo, na Lisistrata. No entanto, é visivel que tanto o autor como o encenador exploram a misoginia social, reflexo de uma sociedade máscula, não fosse o século de Tchekov o da emancipação feminina. António Augusto Barros dirigiu a sua dramaturgia em dois eixos: a exploração das situações misóginas e de azedumes conjugais que forjam uma linha temática, recuperando desse modo alguma unidade isotópica nos fragmentos; e a própria desconstrução dessa linha através da velha técnica d' "o teatro dentro do teatro". E é ai que se encontra toda a mestria, tanto da dramaturgia como da encenação, opções que tornam o espectáculo não num amontoado parcelar de textos, mas numa esfera coesa que regularmente se auto-reflecte e se auto-encena.

Descobrimos ainda na dramaturgia e na encenação do espectáculo uma outra especificidade, que reforça uma certa leitura de encenação, ligando os dramatículos "menores" aos dramas "maiores" tchekovianos. A montagem dos fragmentos apresenta uma intertextualidade formal e subtil entre a encenação dos seis dramas curtos e as peças longas do autor russo. Basta pensarmos naquilo que Tchekov exercita em grande parte da sua obra dramática: a mistura entre o trivial e o sério, tanto nas falas das personagens como na acção em si. Ambas se reflectem no trabalho dramatúrgico do encenador. De facto, António A. Barros consegue estruturalmente converter 0 canto do cisne $\mathrm{e}^{2}$ em ponto de fuga ao ambiente burlesco centrífugo, colocando-o igualmente numa espécie de meta-reflexão da peça sobre si própria. Essa metareflexão sobre o espectáculo é criada, de algum modo, para introduzir na atmosfera hilariante um "ar fresco, sereno e 'filosófico'". Ao impor 0 canto na segunda parte 


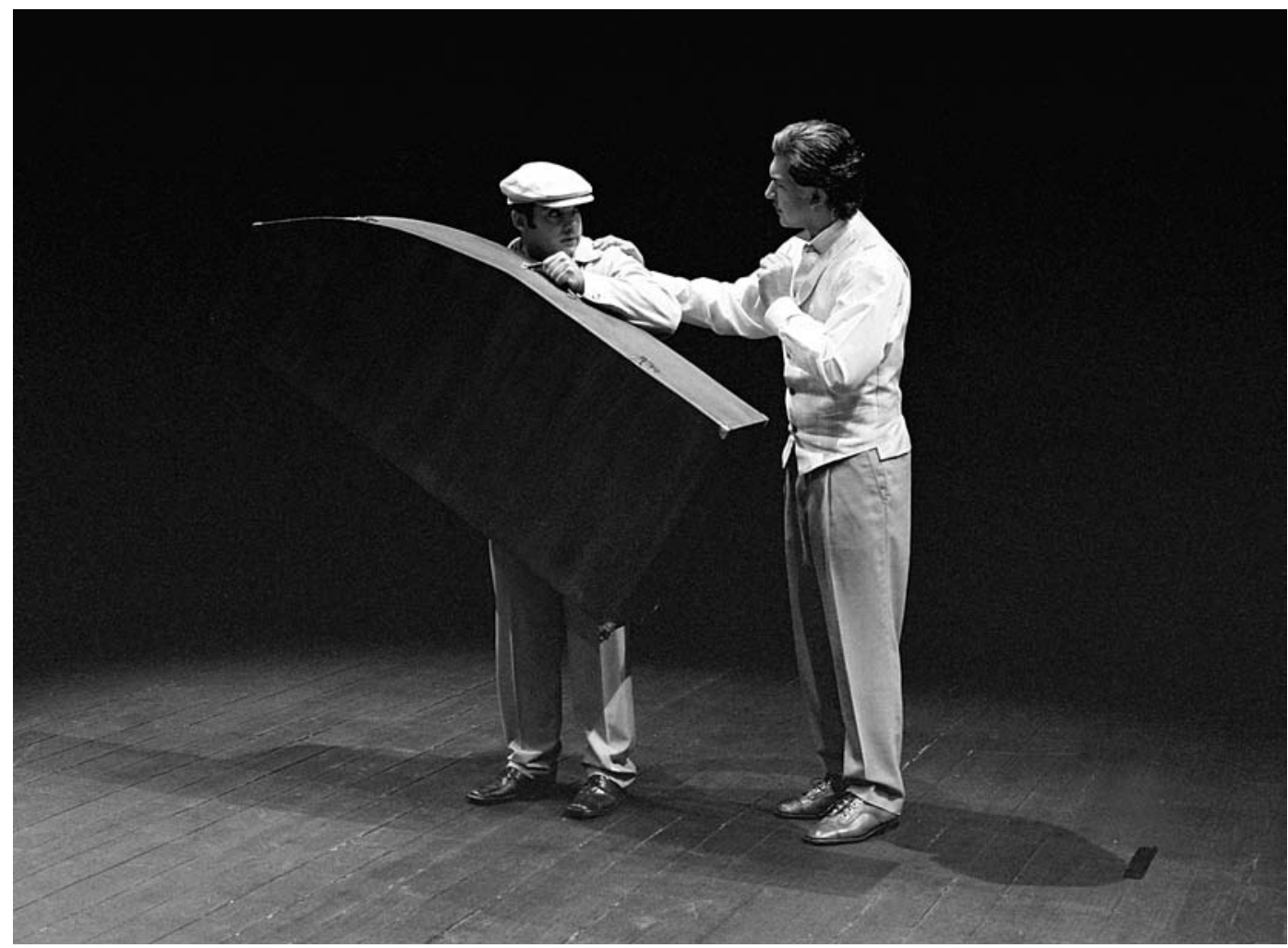

Tchekov e $a$ arte menor (Trágico à força), de Tchekov, enc. António Augusto Barros, A Escola da Noite, 2007 (Miguel Magalhães e Pessoa Júnior), fot. A Escola da Noite. do espectáculo de uma forma fragmentada, servindo de linha de costura ao todo, o encenador corrobora um procedimento também presente nas peças "maiores" do autor; sabemos como o emprego dramático da técnica contrapontistica se traduz num paladar tchekoviano agridoce que é muito particular ao autor russo. Assim, a comicidade da misoginia, das perturbações conjugais, e as próprias situações vaudevilescas, assumem na segunda parte da representação o poder de desnivelar a própria ilusão superficial dos dramas cómicos, reencaminhandoos para uma dimensão poética criada pela fragmentação d'O canto do cisne.

A encenação apresenta igualmente idiossincrasias interessantes e que recriam o universo do dramaturgo russo. Se, por um lado, o público é transportado para uma ilusão criada pela coesão da(s) fábula(s), por outro, o trabalho de encenação visa a descontrução teatral. Com excepção d'0 canto do cisne, que assume contornos específicos, cada dramatículo é também cenicamente cortado pelo seu predecessor. Esses cortes são efectuados através da movimentação física dos suportes da plateia, dividida em quatro partes (uma em cada canto), movimento possibilitado por actores-mecânicos, com severas configurações meyerholdianas (sempre prontos ao trabalho físico de operário), como se o encenador pretendesse com aqueles homenagear um outro homem do teatro, compatriota de Tchekov. Assim, a encenação reserva a cada plateia uma perspectiva diferente para cada dramatículo, podendo estabelecer um paralelismo entre o espectáculo fragmentado e um público igualmente estilhaçado no seu espaço. É importante sublinhar que a encenação se constrói, em parte, à volta do"teatro dentro do teatro". Aliás, essa opção, tão frequente no barroco europeu, torna-se evidente, em primeiro lugar, com a introdução dos actores-operário e, em segundo, com a manipulação astuta d'O canto do cisne, cujas personagens representam, elas próprias, os agentes teatrais, através de um velho actor e do (seu) ponto que encarna simbolicamente a memória perdida do artista. Porém, ao contrário das outras peças, as personagens d' 0 canto transbordam o seu espaço cénico para povoar, embora em sombra, os outros dramatículos. Essas sombras, presenças quase tétricas, existem para lembrar que, no fim de contas, Tchekov e $a$ arte menor não trata apenas de problemas sentimentais entre os sexos ou ainda de outras situações burlescas, essas sim, "menores", mas também do teatro e da arte; e seria algures neste palco vital da arte que a própria sombra de Tchekov poderia pairar.

0 final contribui igualmente para esse jogo do"teatro dentro do teatro", ao acentuar o encontro entre a ilusão teatral e a realidade não ficcionada, no momento em que são erguidas as pernas das bambolinas, deixando transparecer a estrutura do edificio teatral. Tal estrutura devolve aos olhos dos espectadores a cama de Svetlovidov, no meio do aparato técnico do próprio teatro: assim podemos ver como as personagens que viveram ali durante três horas morrem junto com o velho actor adormecido.

$\mathrm{Na}$ verdade e como o podemos constatar, O canto do cisne representa um elemento fundamental, tanto na dramaturgia como na encenação de António Augusto Barros e será, talvez, esse Estudo dramático em um acto o elevador artístico que torna essas peças "menores" em fragmentos de uma peça "maior", onde as ninharias divertidas dramáticas alcançaram, pela mão simétrica de Tchekov e a arte menor, o desafio artístico e intelectual dos dramas clássicos tchekovianos. 